\title{
Research on Economic Theory and Implementation Method of the Financial Inclusion in Rural Financial Market
}

\author{
Xiaolin $\mathrm{Li}^{1, \mathrm{a}^{*}}$,Chenggang $\mathrm{Li}^{2, \mathrm{~b}}$ \\ ${ }^{1}$ Business School, Sichuan Agriculture University Chengdu, China \\ ${ }^{2}$ Faculty of Finance, Guizhou University of Finance and Economics Guizhou, China

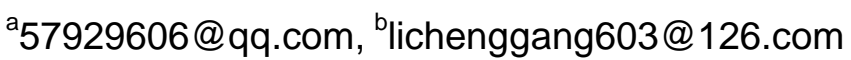

Keywords: Financial Inclusion; Rural financial market; Economic theory; Implementation method

\begin{abstract}
The Internet technology revolution is profoundly affects every aspect of human society, such as people's production and life, habits, and even culture. At the same time, the development of the network economic activity also has a huge impact on the financial sector. And the internet finance has a large impact on traditional financial pattern both in the development idea and operation mode. Based on the study of the present situation and development trend of the financial Inclusion in rural financial market domestic and foreign, the author analyzed the principles of economics, and based on the point, put forward the implementation method and the suggestion on the financial inclusion in rural financial market.
\end{abstract}

\section{Introduction}

Since 2012, internet technology is widely applied in the field of finance, new internet technologies such as big data, cloud computing, social networking, etc. are changing the traditional financial business. The combination of finance and the Internet caused a lot of business model changes, directly promoted the changes of market environment, service mode and the main requirements, and has given rise to the Internet financial. In April 2014, China's state council general office issued<The several opinions on financial service in the development of "the countryside, agriculture and farmers" $>$, we will deepen financial system reform of the rural, develop new rural financial products, services and the financial Inclusion in rural financial market. Therefore, how to apply the Internet finance innovative thinking to the rural financial sector has far-reaching significance on the implementation and development of the financial inclusion in rural financial market.

\section{Literature Review}

The Connotation and Essence of Internet Finance and the Financial Inclusion $n$ Rural Financial Market. At present, the definition of the Internet financial is not very clear. In 2012, Ping XIE put forward the concept of "Internet finance" publicly for the first time, which become the focus of concern of the academia, and has attracted a great deal of controversy. Scholars at home and abroad started from the influence of Internet on the financial industry, analyzed the connotation and essence respectively. Some scholars think that the Internet is just a kind tool of traditional financial services, will not have much impact on the traditional financial sector. Allen think that the Internet is a new kind of financial services and trade way, and on this basis to explore the effects of internet on the financial sector [1]. Some scholars such as Nian WANG and Haijun WANG agreed and developed the idea. They think that finance is the financial activities with the help of modern technology, such as the Internet to realize Internet financial services popularization and extension [2]. Another part of the scholars think that as a new technology the Internet can bring huge impact on the financial industry and service. Shahrokhi think the Internet will have subversive influence on financial industry pattern [3]. Ping XIE and Chuanwei ZOU treat the Internet finance as the third financial financing model different from indirect financing of commercial bank and direct financing in capital market [4]. 《2014 
China financial stability report 》issued by China's central bank clearly defined the Internet finance as: "the financial model to realize financing through the implement of Internet and mobile communications technology". So, most of scholars agree that the Internet finance is not only a traditional financial service with the application of Internet technology, but also including a series of innovation on financial services combined with Internet technology. These innovations are including the innovations of the product, channel and the innovation of operation mode. These innovations for financial services has brought some characteristics different from traditional financial services, such as High efficiency, low cost, low threshold, wide coverage, etc.

There are different understandings about the financial Inclusion in rural financial market at present. In theory, the financial Inclusion in rural financial market is a multidimensional concept, needed to measure in an all-round way with a more comprehensive approach including all information as far as possible [5]. The United Nations put forward the concept of financial Inclusion in the 2005 international meeting of microcredit, which means to provide Effective and comprehensive financial products and services for all social strata and groups, especially for financial consumer groups in rural area which easily ignored by traditional financial. And put forward the concept of inclusive financial system, which means a financial system that provide continuous, effective and comprehensive services for all social strata and groups. In 2006, the United Nations published a book called < Building Inclusive Financial Sectors for Development >, which pointed out of the four basic characteristics in the Inclusive financial system as follows:(1) The participants at all levels such as individuals, families and enterprise have access to a wide range of financial services at a reasonable price, including credit, savings, insurance, investment, transfer, payment, exchange and other financial services.(2)The institutions have a sound financial institutions, strict internal control mechanism, normative industry standard and market supervision mechanism, and the institutions should be subject to the supervision of the market.(3) The financial institutions must have financial sustainability.(4) Have multifaceted competitive financial service providers which can provide wide variety of choices.

The Inner Coupling of Internet Finance and Inclusive Finance. Overall, in spite of that there is no uniform definition on the internet finance and inclusive finance at home, but the existing research is generally believed that the emergence of the internet finance has been brought a sharp rise in efficiency of financial services, which provides convenience for small businesses and individuals, and effectively promotes the innovation and efficiency of the real economy. All of that is advantageous to the implementation of inclusive finance.

First, the characteristics of the internet and inclusive finance has intrinsic coupling. Ping XIE and Chuanwei ZOU think that internet finance show the "long tail" characteristics by expanding the trade possibilities frontier, providing services to a lot of people that traditional finance did not service. Shuguang WANG thinks that, Internet thinking has a degree of influence on rural financial market. He thinks the internet expanded the bank card business functions, contributed to the rise of mobile payment, brought about innovative credit, at the same time has a lot of innovation in financial services of the supply chain ${ }^{[6]}$. Mingzhe ZHANG thinks that low-cost character of internet finance give people who cannot enjoy the service provided by traditional financial system access to financial services, and to improve the degree of financial inclusion ${ }^{[7]}$.

According to the research of Jinlong WANG and Chengyun QIAO, the Internet brought three major positive effect such as "long tail", "catfish effect", and "Matthew effect", which become important reasons for financial inclusion [8]. Scholars generally agree that, financial services at a reasonable price, sustainable supervision of financial institutions, competition in the field of finance are main characteristics of inclusive finance (JinPu JIAO, 2009) [9]. Hai-jun WANG, Nian WANG and Guan DAI think that Internet finance provides a new channel to implementation mainly through microfinance, investment channels, wealth management products [10].

China's rural financial services status: the existing financial products and services is very backward; it remains to be perfect rural financial system; the lack of diversity and types of rural financial services; agricultural insurance coverage and level remains to be improved ${ }^{[11]}$. In general, to carry out the 
reform of the rural financial system must use Internet thinking and combining with the advanced internet technology to promote the establishment and development of rural financial inclusion.

\section{The Analysis on the Economical Principles of Internet Finance}

In this paper, from the supply and demand and the cost of rural financial market, the author analyzed the basic relationship between supply and demand and the cost of rural financial market.

Supply and Demand Analysis of Rural Financial Market. The gap between financial infrastructures of China's urban and rural is very large. The rural financial system is not sound, the existing financial products and services is very backward. There is a big difference in the rural financial market supply and demand relations between traditional rural financial market and the rural financial with development of the internet financial. It is as shown in Fig. 1. The horizontal axis shows the number of rural financial products and services, the vertical axis shows rural financial product price, curve D shows rural financial market demand curve, curve S1 shows traditional rural financial market supply curve, curve S2 shows the supply curve of rural financial market with development of the internet financial.

Supply and Demand in the Traditional Rural Financial Market.

In Fig. 1, curve D shows rural financial market demand, curve S1 shows traditional rural financial market supply, which is divided into two stages: stage (1) is early stage for rural financial market, the rise in the price and products of rural financial were in the reasonable range. But in the second stage, due to many factors such as the backward infrastructures and so on, as the rise in prices of financial products and services, that limited the increase of rural financial products and services, and also limited the development of the rural financial market. At this point, the supply curve and demand curves intersect at point E, Q1 shows the equilibrium quantity, P1 shows the equilibrium price.

Supply and Demand of Rural Financial Market with Developing the Internet Financial.

In Fig. 1, curve D shows rural financial market demand, curve S2 shows the supply of rural financial market with developing the Internet financial. After carrying out Internet finance, rural financial infrastructures were improved, the rural financial system was improved gradually, implemented the competition and diversification of financial products and services, the service level is also higher. The supply capacity of financial products and services significantly increased, so the supply curve move from S1 to S2, curve S2 and curve D intersect at the point $F$. At this point, the equilibrium quantity is $\mathrm{Q} 2$, the equilibrium price is $\mathrm{P} 2$.

After developing the Internet financial by rural financial market, equilibrium point move from $E$ to $\mathrm{F}$, equilibrium quantity increased from $\mathrm{Q} 1$ to $\mathrm{Q} 2$, means the supplying ability of the financial products and services significantly increased. The equilibrium price decreased from $\mathrm{P} 1$ to $\mathrm{P} 2$, means conducive to implementation of financial inclusion. 


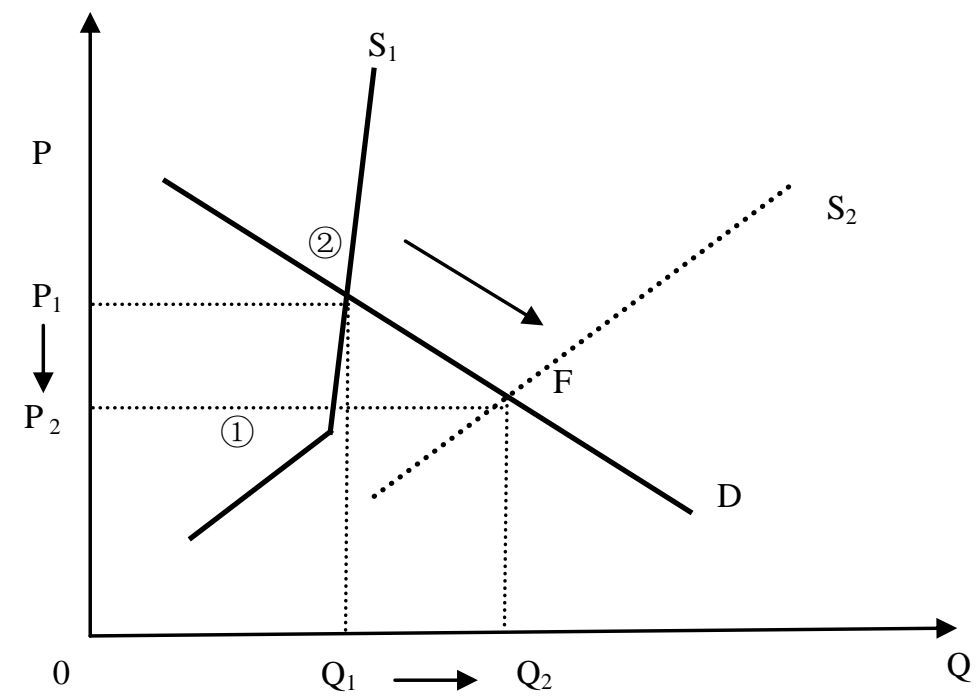

Figure 1. Supply and demand curves of traditional rural finance and Internet finance

Cost Analysis of Rural Financial Market. The cost of the rural financial market can be divided into two parts : variable cost and fixed cost. Cost analysis of the rural financial market can be start from the total cost, variable cost and fixed cost and average cost, as shown in Fig. 2 and Fig. 3.In Fig. 2 , the horizontal axis shows the number of rural financial products and services, the vertical axis shows the cost of rural financial product, Curve FC shows the fixed cost of rural financial market, Curve VC shows the variable cost of traditional rural financial market, Curve TC shows the total cost of rural financial market which was carried out Internet financial . Fixed costs FC include the costs of rural infrastructures construction, the financial system infrastructures and the Internet infrastructures construction, etc. Initial outlay is very high, once it is completed, such costs are no longer changing anymore, as shown in Fig. 2. Variable costs VC include the costs of financial organizational structure and service supporting system, etc. With the increase of number of financial products just when the opening of a financial institution, these costs rise fast, when achieve optimum efficiency of configuration, these costs rise slowly, as to the limit of service capacity in the end, these costs rise fast again. Due to the total cost is the sum of variable cost and fixed cost together, as shown in formula (1), and the fixed cost is constant, so the shape of the curve TC is consistent with the curve VC, as shown in Fig. 2.

$$
\mathrm{TC}=\mathrm{VC}+\mathrm{FC}
$$

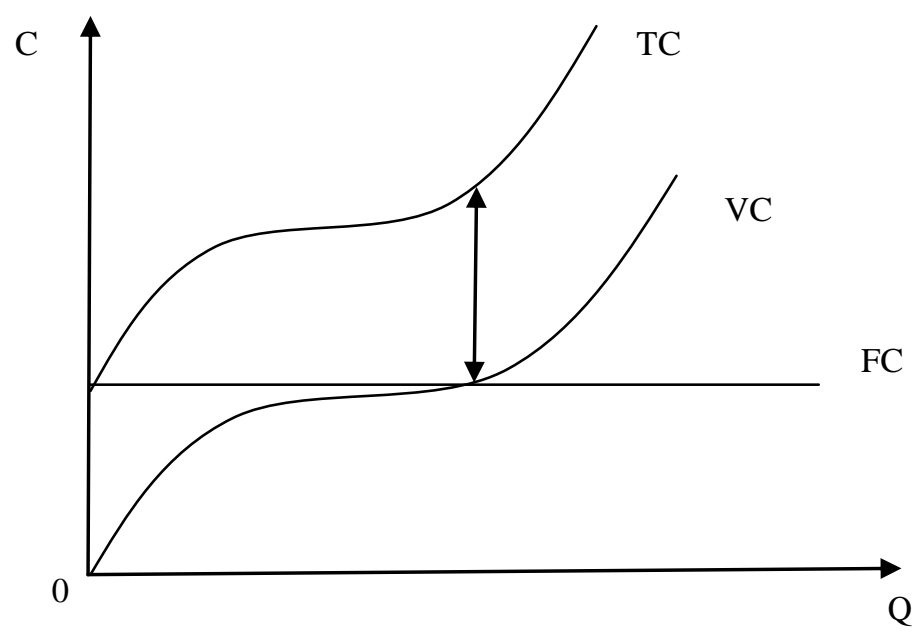

Figure 2. Cost curve of traditional rural finance and Internet finance 
In Fig. 3 the horizontal axis shows the number of rural financial products and services, the vertical axis shows the cost of rural financial product, curve AFC shows the average fixed cost of rural financial market, curve AVC shows the average variable cost of traditional rural financial market, curve ATC shows the average total cost of the rural financial market with developing the Internet financial. The fixed cost will no longer change once input, therefore, with the increasing number of products and services in the rural financial market, the average fixed costs AFC of unit products and services will be smaller and smaller. With the input of various elements which constitute the variable cost, average variable cost reduced at first, and to a minimum when the services and products were provided most efficient, and then increased at last. Due to the average total cost is the sum of average variable cost and average fixed cost together, as shown in formula (2), so the shape of the curve ATC is consistent with the curve AFC at first, when the average fixed cost reduced to very small, the shape of the curve ATC is consistent with the curve AVC.

$$
\text { ATC }=\text { AFC }+ \text { AVC }
$$

After implanting the internet thinking into rural financial market, as the increasing ability to supply financial products and services in rural financial market, the number of products and services increase from $\mathrm{Q} 1$ to $\mathrm{Q} 2$, the average total cost correspondingly dropped from $\mathrm{K}$ to $\mathrm{H}$, the cost dropped from $\mathrm{C} 1$ to $\mathrm{C} 2$. Therefore, from the perspective of the cost, with a significant reduction in the cost of financial products and services, the market will be more active. All of these means conducive to implementation of financial inclusion.

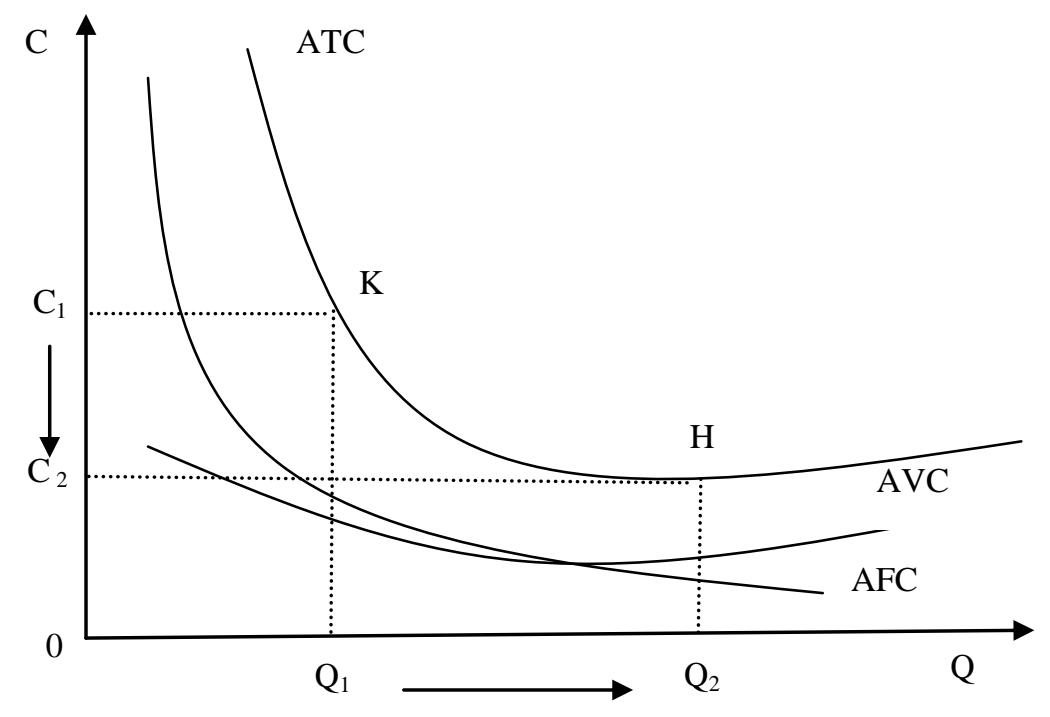

Figure 3. Average cost curve of traditional rural finance and Internet finance

\section{Analysis on Difficulties and Implementation Path of the Financial Inclusion in Rural Financial Market}

\section{Difficulties of the Financial Inclusion in Rural Financial Market}

Traditional financial institutions struggle with the emerging financial organization for interests. In economic and society, any reform will meet resistance. To break through the obstacles, emerging technology need a variety of conditions, and there is bound to experience an exciting game between emerging financial institutions and the traditional financial institutions.

The difficulties brought about by the rural market structure characteristics. The dispersed rural financial market structures and the complexity of departments and regional diversity, make the integration of information resources difficult.

Inappropriate government regulation system. Because of the imperfect rural financial markets, government agencies need to build order to correct market failure. But the inappropriate government management system may cause such problems as too strict supervision and regulatory mismatch. 
The risk and hidden dangers brought by technology. The network infrastructure construction is still not perfect so far, technology is not mature, the resulting security risk is inevitable [6].

Credit problems caused by imperfect credit system in our country. The development of the Internet financial claim to very strict credit system, we also need a relatively long process to build the credit system of our country.

Other unpredictable risk.

The Implementation of the Rural Inclusive Finance. At present, China's rural financial market participants are mainly individuals, businesses, government and rural financial institutions [12], In order to realize rural inclusive finance, it need to set up the organic system work together by participants and adapt the development of the Internet financial environment system, as shown in Fig. 4.

Based on the business model of Internet thinking. In rural financial market, the network banks, finance in retail e-commerce, financial services in online payment platform, internet financial platforms (P2P) and so on can be carry out.

The environment system requirements of inclusive finance, such as good economic environment, political environment, cultural environment conducive to innovation, credit environment and so on.

The requirements about rural financial institutions, such as flat organization, rationalization of business process, Sound of payment system, dynamic credit management system, etc.

The requirements about government agency. Government agencies should play an important role in credit system, the infrastructure, system supply, regulatory monitoring, industry standards etc.

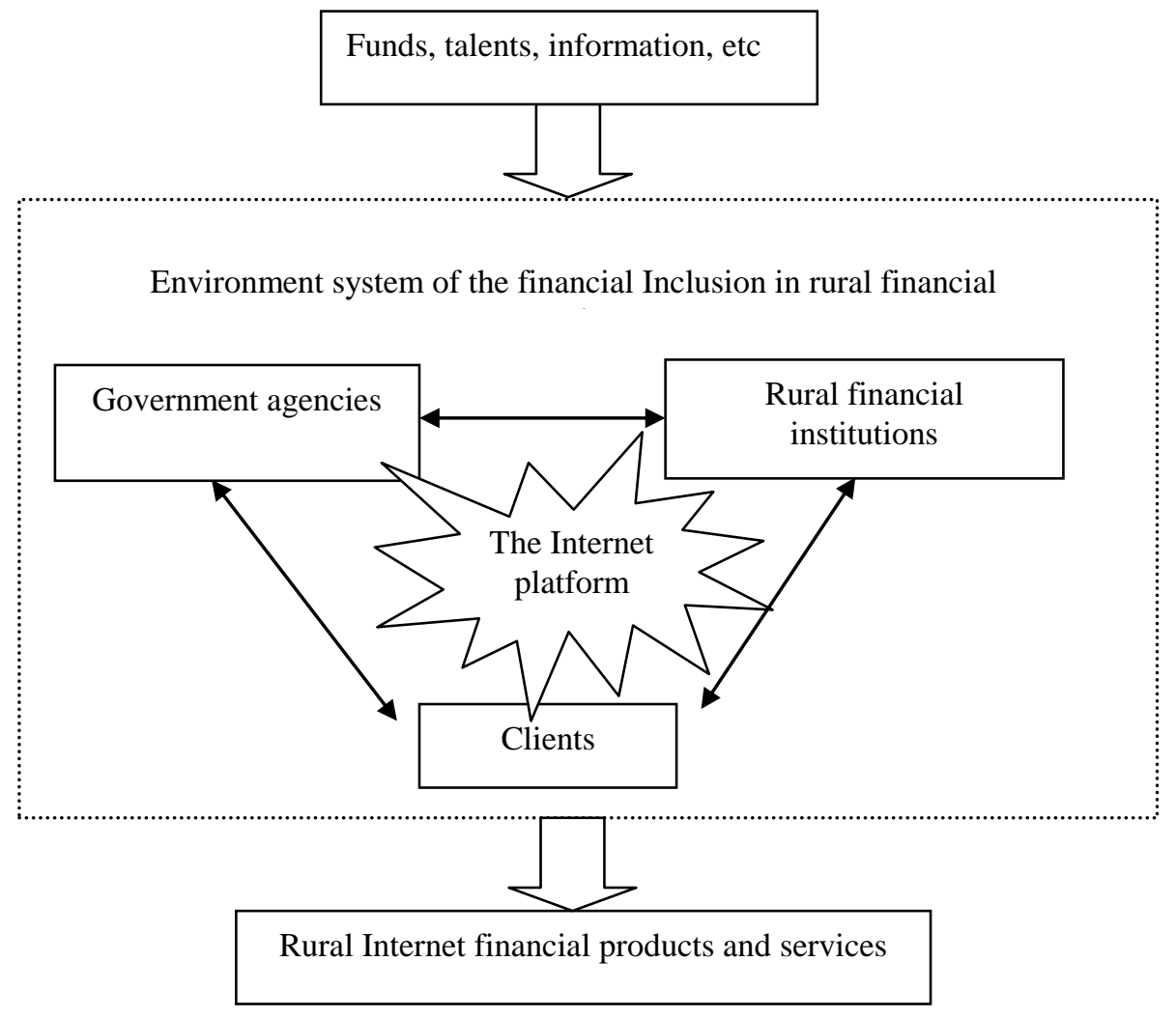

Figure 4. Implementation method and path on the financial Inclusion in rural financial market

\section{Summary}

Based on the study of the present situation and development trend of the financial Inclusion in rural financial market domestic and foreign, the author analyzed the principles of economics, and based on this, put forward the implementation method and the suggestion on the financial inclusion in rural financial market. 


\section{References}

[1] Allen F., J. Mc Andrews and P. Strahan. E-finance: An Introduction [J]. Journal of Financial Services Research, 2008, 22(1/2):5-27.

[2] Nian WANG, Haijun WANG. "Chinese" Internet finance: Technical foundation and basic patterns [J] .Southwest Finance, 2014(6):43-46.

[3] Shahrokhi M. E-finance: Status, Innovations, Resources and Future Challenges [J] . Managerial Finance, 2008, 34 (6): 365-398.

[4] Ping XIE, Chuanwei ZOU. Research on the model of Internet financial [ J ] .Financial research, 2012 (12): 11-22.

[5] Sarma M. Index of Financial Inclusion [R].Indian Council for Research on International Economic Relations, Working Paper, No. 215, 2008.

[6] Shuguang WANG, Xinya KONG, Qiyao ZHANG. The financial Inclusion with the thinking of internet finance $[\mathrm{J}]$. Chinese financiers, 2014(6):125-126.

[7] Mingzhe ZHANG. The basic characteristics and application of the Internet finance [J].Innovation, 2014(2): 58-61.

[8] Jinlong WANG, Chengyun QIAO. The influence and development of Internet finance, traditional finance and financial inclusion[J].New horizons, 2014 (5) : 14-16.

[9] JinPu JIAO. The construction of Chinese financial inclusion system[M]. China's Financial Press, 2009.

[10] Haijun WANG, Nian WANG, Guan DAI. Internet financial with the background of financial inclusion- The theory and policy analysis[J].Journal of Shanghai financial institute, 2014 (4) : $32-44$.

[11] Research team on rural finance service of people's bank of China. Research on the status quo and the development direction of China's rural financial services[J]. Tsinghua financial review, 2015(7):22-25.

[12] Yuming ZHANG, Hongsheng WANG. Research on the Internet financial characteristics and mechanism of action under the perspective of complex adaptive system[J]. Journal of Shandong University (philosophy and social sciences edition), 2014(5):023-032. 